\title{
Collage y simulacro. Apuntes sobre el teatro documental de Lola Arias
}

\author{
Universidad de Sonora \\ Fernanda Galindo \\ Diana Brenscheidt genannt Jost
}

\section{Introducción}

Desde su surgimiento en la década de los ochenta en EE.UU. y Europa, la crítica posmoderna ha estado en relación directa con las manifestaciones artísticas, encontrando inspiración en ellas y viceversa (véase Huyssen, 1998). Mientras continúa la discusión sobre si la posmodernidad es una etapa histórica en sí misma o simplemente se trata de la última etapa de la modernidad -sin que el dilema haya sido resuelto- observamos que la crítica posmoderna ha cambiado la concepción, producción, difusión y recepción del arte, además de diluir la separación arte-vida y artista-público. Aunque autores latinoamericanos han expresado sus dudas sobre la pertinencia de la aplicación del concepto de posmodernidad a la vida en América Latina (véase Yúdice, 1989), no hay duda de que las ideas artísticas, sociales y políticas relacionadas con lo posmoderno han tenido repercusiones en las prácticas del arte latinoamericano. Identificamos aquí, entre otras, la línea del teatro documental como una práctica artística influida por la crítica posmoderna, la cual encuentra su expresión en elementos y técnicas específicas.

Así pues, a partir del concepto de postmodernidad definido por Lyon (2000), este trabajo tiene el objetivo de analizar los conceptos de collage y simulacro -extraídos por el teórico escocés como ideas que emergen de lo posmoderno- en cuatro obras de teatro documental de la directora de teatro, cineasta y performer, Lola Arias (nacida en Buenos Aires, 1976): Mi vida después (2009), Melancolía y manifestaciones (2012), El año que nací (2012) y Campo minado (2016). Más allá de la crítica que hace el teatro documental del teatro moderno, misma que coincide con las ideas de la crítica posmoderna de origen europeo y estadounidense, analizamos la manera en que los conceptos de collage y simulacro tienen lugar en las obras de la directora argentina.

\section{Hacia un concepto de postmodernidad}

De acuerdo con Lyon (2000), el debate sobre la postmodernidad surge en los años ochenta a través de disciplinas como la filosofía, para después manifestarse en el arte, la arquitectura, la crítica de cine y de literatura. Aún de la temporalidad referida, Lyon encuentra fundamentos de ese concepto en algunos teóricos del siglo $\mathrm{XIX}^{1}$, a quienes considera adelantados en su pensamiento y de los cuales retoma conceptos importantes para su definición. En términos generales, según el autor, la postmodernidad no es más que un "agotamiento de la modernidad" (p.

\footnotetext{
${ }^{1}$ Lyon (2000) menciona entre los "adelantados" a la postmodernidad, es decir, quienes proporcionaron algunas ideas sobre lo que era antes de que apareciera el concepto en los años ochenta, a filósofos como Friedrich Nietzsche (1844-1900), Martin Heidegger (1889-1976) y Georg Simmel (1858-1918).
} 
27) que tiene que ver con fenómenos culturales y sociales que se conjugan entre sí. Si la modernidad confía en la razón y el progreso, propiciando un desarrollo científico, tecnológico y un consumo exacerbado, la postmodernidad cuestiona las doctrinas heredadas y la razón.

Entre los principales rasgos de la postmodernidad mencionados por Lyon (2000), se encuentra el collage como "el estilo posmoderno" (p. 38), mismo que proviene de la perspectiva deconstructivista de Derrida y que -siguiendo a Lyon- parte de la pérdida de autoridad de los autores sobre los textos, de manera que, "una vez que el texto es público, es ampliado por las interpretaciones de otros, escapando a todos los esfuerzos por amarrarlo a la verdad o fijar su significado", lo que implica un proceso de reelaboración de los textos realizados por quienes los consumen. Ese estilo de collage implica, de acuerdo con lo anterior, una constante reconstrucción de textos, mezclándose entre sí, entendiendo por texto "cualquier artefacto cultural" (p. 38).

Por otra parte, Lyon se refiere al simulacro, concepto relacionado con la pérdida del acceso a lo real, cuya teoría es desarrollada por Baudrillard (1978). Este término hace referencia a una realidad incierta, a la que es imposible acceder ya que se ha perdido el referente, por lo que se propone un juego de representaciones de lo real que hacen evidente la construcción, es decir, la simulación, como un proceso alternativo.

\section{Lola Arias y el teatro documental}

Lola Arias (nacida en 1976), es una de las principales representantes de teatro documental en Argentina. El teatro que la directora desarrolla tiene su antecedente histórico en la Alemania de principios del siglo XX en el teatro político de Erwin
Piscator (De Vicente, 2016). En Latinoamérica, el teatro documental aparece en los años setenta debido a la influencia de la teoría del dramaturgo sucesor de Piscator, Peter Weiss (Bravo-Elizondo, 1982). Aunque se han ubicado algunas de las características de esa teoría en las obras actuales, siguiendo a Brownell y Hernández (2019) el teatro documental surge como término en la Argentina del siglo XXI a través de la búsqueda experimental de la directora que fue maestra de Arias, Vivi Tellas, pues "teatro documental era una expresión que no estaba siendo utilizada en ese momento" (p. 26).

Para De Vicente (2016), uno de los rasgos más importantes que definen el teatro documental es el uso o producción del documento -llámese texto, material archivístico, objetos, entre otros- que hace alusión a un momento concreto, a su realidad, es decir, que está "ligado a la coyuntura de su tiempo"( p. 39), y que tiene "un valor social, político o económico, un valor explicativo" (p. 39), además de que niega la fábula "imponiendo a la dramaturgia unas limitaciones en la invención" (p. 39). En el teatro de Arias -como en el caso de su precursora Vivi Tellas- se hace uso del documento pero ampliándolo a las personas, es decir, son ellas quienes cumplen la función de archivo, aunque también se hace uso de otros materiales como fotografías, textos y filmes, mismos que son utilizados como "fragmentos de vida" (Brownel, 2012, p. 2). La selección de esos documentos se da a través de un procedimiento que implica la búsqueda de las personas-archivo para trasladarlas a la escena junto con sus historias. La mayoría de las veces no se utilizan actores profesionales, sino gente común, poniendo en duda con esa técnica la tradicional separación binaria entre artista y público mantenida por el teatro moderno.

La idea de que el documento hace alusión a un momento concreto y a una realidad, señalada por De Vicente, 
denota el vínculo de lo documental con lo histórico comprendido como un suceso marcado en el tiempo; y, por otro lado, con la concepción de una realidad posible de recuperar a través del teatro. La alusión a lo histórico, en el caso de Arias, se observa en la referencia que hay en sus obras a momentos concretos, especialmente a la época de la Dictadura. Sus personajes -personas comunes que cuentan sus historias en escena de acuerdo a los lineamientos establecidos por la directora- están claramente enmarcados en un contexto y una época, a las cuales hacen referencia; o bien, que están en la base de sus conflictos. En cuanto a la realidad, el problema se vuelve complejo, sobre todo si se observa bajo la perspectiva del posmodernismo.

La relación entre el teatro documental y la posmodernidad ha sido observada por varios teóricos. Brownell y Hernández (2019) señalan que en este teatro no existe una frontera clara entre ficción y realidad. Hernández (2011) incluso llega a la conclusión de que "el documento ahora sirve como un punto de partida donde tanto la realidad como la ficción se ponen a prueba" (p. 117), así como también se cuestiona la idea de propagar una verdad. En lo anterior -siguiendo a la teórica- se encuentra una relación con las ideas de lo posmoderno. Citamos a Hernández en extenso por la relevancia de lo enunciado:

En el siglo XXI, este teatro inventa desde lo real, y así comparte a grandes esquemas las mismas características regidas por el posmodernismo, incluyendo la subjetividad, la contradicción de poner en escena lo real dentro de un marco ficticio, el cuestionamiento de la relación entre la verdad y los hechos, la posibilidad del azar como resultado inesperado, la conexión entre la historia privada y pública como dos partes de los mismos hechos documentales y la posibilidad de que el actor llegue a ser una representación de sí mismo (p. 117).
Desde esta perspectiva, se destaca en este teatro la función de cuestionamiento que, a nuestro modo de ver, probablemente se relacione con la introducción de la subjetividad en lo documental al incorporar en él a las personas-archivo -ya se trate de actores no profesionales o de actores que cuenten desde su propia subjetividad-. Para Hernández, el aspecto cuestionador choca con la intencionalidad que ha tenido el teatro documental de construir algo verídico, presentándose como un dilema. De Vicente (2016), por su parte, reconoce lo posmoderno en el teatro documental describiendo la manera que afecta la pérdida del objeto que da origen a que se pierdan la historia y la realidad -su materialidad-, pues constituyen los tres elementos con los que ese teatro trabaja. Pero, a diferencia de Hernández -que destaca el cuestionamiento de lo real, la ficción y la verdad- para De Vicente el teatro documental posmoderno "está obligado a hacer un movimiento crítico en dos direcciones: la primera, restituyendo la realidad; la segunda, restituyendo la historia porque a pesar de la posmodernidad seguimos seres radicalmente históricos" (p. 42). Para la teórica el mecanismo es poner en duda, mientras que para De Vicente es reestablecer lo perdido.

Lejos de indagar en la polémica que desatan ambos puntos de vista, queda claro que es posible hablar de un teatro documental posmoderno en el cual algunas de las nociones que lo caracterizan se ponen en duda, independientemente de los mecanismos utilizados, y que en todo caso deben observarse en los casos concretos de obras y autores a estudiar.

En este trabajo seguimos la idea de Hernández (2011) sobre el cuestionamiento de lo real debido a su relación con el teatro de Arias, pues observamos que la creación de la directora busca poner en evidencia la construcción de lo real, po- 
niéndolo en duda. Además, la teórica sugiere la relación entre la idea de simulacro de Baudrillard y el teatro documental, pues éste último, al confrontar la verdad del archivo, lleva a extremar la simulación.

Si seguimos la idea de Jean Baudrillardque la verdad, el referente y las causas objetivas han dejado de existir y, por ende, han abierto camino al estímulo de la simulación-, el teatro documental de hoy en día expande esta noción y así confronta el valor del archivo como verdad absoluta (p. 117).

Cabe observar, bajo esa perspectiva, la manera en que opera el mecanismo de la simulación en las obras concretas, así como indagar de qué manera el concepto del simulacro es reformulado. Por último, sobre el valor social y político del documento que señala De Vicente (2016) como uno de los rasgos esenciales del teatro documental, este aspecto, a nuestro modo de ver, se manifiesta en el teatro de Arias a través de la implicación de personas reales y, por otro lado, en tanto que busca impactar en la realidad social, cerrando de esa manera la brecha entre arte y vida - $\mathrm{O}$ arte culto y arte popular- sostenida por el modernismo (Huyssen, 1998).

\section{El collage: confluencia heterogénea de textos}

Ya en la diversidad de disciplinas a las que Arias se ha dedicado se puede observar un interés por lo heterogéneo que repercute en el carácter híbrido de su teatro. Además de drama, escribe también poesía, narrativa y diversos artículos; ha sido autora e intérprete de los discos El amor es un francotirador (2007) y Los que no duermen (2011); en 2018, incursiona en el cine con el documental Teatro de guerra (2018), basado en la obra teatral Campo minado (2016).
Comprendiendo el collage, de acuerdo con Lyon (2000), como la reconstrucción de textos y la mezcla de los mismos, en el teatro de Arias se observa, además de la incorporación de las distintas disciplinas que practica, la mezcla de distintos géneros y recursos tomados tanto del arte como de lo cotidiano, de manera que no se puede hablar de un solo género o un solo estilo que conforme un todo unívoco. En Melancolía y sus manifestaciones (2012), obra que trata sobre la madre de Arias, quien padeció diversas depresiones e intentos de suicidio a lo largo de su vida, se observa la búsqueda de yuxtaposición de lo heterogéneo. Al inicio, la directora introduce la historia contándola en primera persona de pie frente a un micrófono. Situada en el proscenio, en un espacio que se distingue del de la escenificación, se acerca a lo performático, no sólo como narradora de una historia que enuncia como real, sino también al interpretar canciones acompañada por un guitarrista.

Lo cinematográfico es otro de los elementos incorporados a la obra. Arias (2019) crea una caja dentro del escenario en la que las escenas se acompañan de fotografías, canciones, objetos de su madre, filmes "como si fuera un libro ilustrado sobre la melancolía" (p. 47). Dentro de esa caja que recuerda a los límites del cuadro de una película, no sólo se presentan los objetos característicos de lo documental -entre los que también está el material fílmico- sino también algunos recursos del cine, como la estructura en capítulos cuya aparición tiene lugar por medio de letreros luminosos colocados en la parte superior de la caja, como si se tratara de los títulos de crédito; y el uso de una grabación de la voz de la madre de Arias utilizada como en off.

En Mi vida después (2009), obra en la que seis personas nacidas en los años setenta reconstruyen la juventud de sus padres y que constituye un retrato sobre la dic- 
tadura argentina construido a través de historias particulares, la idea de collage aparece en el uso del video, la estructura en escenas como secuencias y la intervención de los videos en tiempo real, es decir, mientras transcurre la obra. Está también el carácter performático que se muestra a través de elementos aleatorios, lo que se observa cuando le preguntan a una tortuga si habrá una nueva dictadura en Argentina soltándola frente a las dos opciones -negativa y positiva- dibujadas en el suelo, que la tortuga tomará casualmente. Por otra parte, como en el caso de Melancolía y otras manifestaciones, aquí se utilizan varios objetos, en este caso fotos, cartas, ropa usada, relatos y cintas grabadas de las personas que cuentan su propia historia. Cabe acotar aquí que existe un proceso de selección de las historias, es decir, no se trata de una trasposición directa del testimonio real a la escena. Es la directora quien hace ese proceso que Brownell (2012) define como de mediación de la mirada. En el trabajo de la directora con sus intérpretes, se observa su intencionalidad del collage y lo híbrido, buscando mezclar diferentes tonos, géneros y recursos. Arias ha descrito su trabajo como el de una terapeuta-directora, que pide a su paciente realizar determinadas acciones:

Vístase con una prenda de su padre y reconstruya su muerte usando a sus compañeros [...] Haga su árbol genealógico en forma de coreografía [...] Filme el exilio de sus padres como una película de género, un melodrama, un policial, un film de ciencia ficción (Arias, 2019, p. 45).

En El año que nací (2012), la directora toma como modelo Mi vida después y lo lleva a Chile para reconstruir la dictadura de ese país. Ahí, un grupo de jóvenes chilenos nacidos en la dictadura reconstruyen la vida de sus padres a través de fotos, cartas, cintas, ropa usada, historias y recuerdos; además de performance, mú- sica y videos en vivo, de la misma manera que hace en la primera obra. Lo que cambia aquí son los intépretes, las historias y, por supuesto, el contexto.

En Campo minado (2016), veteranos argentinos e ingleses de la guerra de las Malvinas se reúnen en el escenario para recordar la guerra vivida por cada uno de ellos. Aquí el collage aparece en la utilización de videos, entrevistas, narración en off, performance y, por supuesto, una diversidad de objetos personales de los intérpretes. En esta obra, la incorporación de lo cinematográfico es mayor, ya que el escenario se constituye como un auténtico set de filmación. Por otro lado, la obra se estructura de acuerdo a entrevistas grabadas en tiempo real durante la escenificación, utilizando este recurso del cine documental. Aquí, el uso de elementos de distinta naturaleza en la escena no sólo tiene que ver con el collage y la confluencia de textos heterogéneos que implica, sino también se relaciona con lo expuesto por el dramaturgo francés Antonin Artaud (1896-1948) en El teatro y su Doble (1978), quien propone "resucitar una idea del espectáculo total, donde el teatro recobre del cine, del music-hall, del circo y de la vida misma lo que siempre fue suyo" (p. 97). Teatro y vida se mezclan en una escenificación que hace ver un mundo en el que no caben las definiciones cerradas ni las fronteras.

\section{Simulacro: el mecanismo ante una realidad disipada}

Según Hernández (2011), en el teatro documental no existen las fronteras entre lo real y la ficción. En ese espacio híbrido "es donde el nuevo teatro documental genera espacios críticos que cuestionan, analizan y manipulan los hechos verídicos [...] estos mismos espacios críticos desvanecen y desestabilizan el sentido de lo real hasta muchas veces llegar a 
la parodia" (p. 118). Lo anterior significa que los hechos referidos en una obra documental no pueden distinguirse plenamente de la ficción creada por sus autores, lo que genera la imposibilidad de concebir una verdad unívoca. La realidad -siguiendo a Hernández- se quebranta.

Es en esa desarticulación de lo real que se encuentra la relación con el concepto de simulacro de Baudrillard (1978), quien lo describe como la imposibilidad de acceder a la realidad y por tanto, de escenificar la ilusión de la misma: "La imposibilidad de escenificar la ilusión, es del mismo tipo que la imposibilidad de rescatar un nivel absoluto de realidad. La ilusión ya no es posible porque la realidad tampoco lo es" (p. 43). En el caso de Arias, ella utiliza la simulación como un juego teatral que conlleva la idea de la imposibilidad de una realidad fiel. No es gratuito el hecho de que en todas sus obras trabaje con la memoria, asignándole la particularidad de las historias contadas por personas reales, interfiriendo en ella a través de esenas «representadas», creando así una ironía que muchas veces lleva al humor y la parodia.

En Melancolía y otras manifestaciones, Arias incorpora el trabajo de una actriz para interpretar el papel de su madre. El simulacro se observa aquí en hacer evidente la representación como un recurso, pues la directora presenta a la actriz en escena señalándola como una intérprete. Con ello parece decirnos que aunque la historia está basada en un suceso real en tanto que autobiográfico -una realidad subjetiva-, esa realidad es inaccesible, por lo que necesario recurrir a la simulación. Aquí se encuentra también una relación con la idea de «el Doble» de Artaud. Cuando la madre de Arias se niega a participar en la obra que relata su vida, la directora invita a una actriz en su lugar, pero se niega a que actúe, pues "quería que estuviera en escena «en lugar de», como una doble" (Arias, 2019, p. 47). La actriz aparece en el escenario al abrirse unas cortinas en las que hasta ese momento se proyectaba su imagen, en un procedimiento semejante a una disolvencia cinematográfica. Con ella, aparece también el hombre que hasta entonces la estaba filmando en tiempo real. La actriz habla como si fuera la madre de Arias, presentada por ella como lo que es: una actriz, no su madre. La voz que escuchamos es la de su madre en realidad, reproducida en off, por lo que la actriz mueve los labios en un juego parecido al marionetista que mueve los hilos para que su marioneta se mueva. Aparece la máscara; la simulación se hace evidente como un mecanismo que solventa la realidad diluida. No hay engaño. Pareciera tratarse de un teatro basado en la alquimia, como un «Doble» de una realidad lejana a lo cotidiano:

Allí donde la alquimia, por sus símbolos, es el Doble espiritual de una operación que sólo funciona en el plano de la material real, el teatro debe ser considerado también como un Doble, no ya de esa realidad cotidiana y directa de la que poco a poco se ha reducido a ser la copia inerte, tan vana como edulcorada, sino de otra realidad peligrosa y arquetípica (Artaud 1978, p. 55).

En su teatro Arias presenta ese doble de la realidad, no como un «reproductor» de la misma, sino como medio para jugar con ella, confrontarla, atravesarla por la alquimia, transmutarla. Una realidad que no es la del naturalismo, mismo que, de acuerdo con Pavis (1998), se propone dentro del contexto del positivismo en el que surge "observar la sociedad desde un punto de vista clínico o fisiológico que, de hecho, la encierra en un determinismo no dialéctico" (p. 311). Aquí, por lo 
contrario, es un teatro que no se dirige a la razón -desgastada en la modernidad, rechazada por la postmodernidad- sino a los sentidos, y que se parece mucho al teatro pretendido por Artaud.

Queremos transformar al teatro en una realidad verosímil, y que sea para el corazón y los sentidos esa especie de mordedura concreta que acompaña a toda verdadera sensación. Así como nos afectan los sueños, y la realidad afecta los sueños, creemos que las imágenes del pensamiento pueden identificarse con un sueño, que será eficaz si se lo proyecta con la violencia precisa. Y el público creerá en los sueños del teatro, si los acepta realmente como sueños y no como copia servil de la realidad, si le permiten liberar en él mismo la libertad mágica del sueño, que sólo puede reconcer impregnada de crueldad y terror (Artaud, 1978, pp. 96-97).

Audición para una manifestación (2017) es un performance en el que puede observarse claramente la idea de simulacro. Arias convoca al público en general a recrear una manifestación del pasado. La gente actúa o representa en vivo, es grabada y proyectada en vivo. No hay ensayos. Las preguntas de partida son: “¿Dónde estaba cuando todo pasó: estuve ahí, lo vi por televisión, me lo contaron? ¿Qué imágenes me quedaron? ¿Cómo actuaría en esa multitud? ¿Hasta dónde estoy dispuesto a llegar?" (Arias, s.f.). En dichas preguntas se observa la intención de la directora, empujándo al público a la interpretación de sí mismos a través de la exploración de sus recuerdos. En esta obra, se ve cómo, ante la imposibilidad de acceder a la realidad, se explora la simulación a través del recurso de la ironía. La directora despoja esa limitación de la realidad y la afronta sin nostalgia, como un juego cargado de humor.

Retomando a Baudrillard (1978), la simu- lación puede ser más poderosa que la realidad, actuando sobre ella y rebasándola. Aunque en las obras de Arias se encuentra un juego con la simulación que se expresa en los actos performáticos de los actores, a través de la recreación de escenas o de la puesta en escena de sus recuerdos, también puede verse que su obra genera un impacto sobre la realidad fuera del teatro. Es el caso de la obra Mi vida después, en la que Vanina Falco, una de las intépretes, lleva a cabo la lectura de legajos del juicio contra su padre que estaba sucediendo en la realidad, refiriendo que era imposible para ella declarar debido a una prohibición legal. Tiempo después, a fuerza de repetir la misma escena, su abogado logra quitar la prohibición, lo que la lleva a declarar contra su padre, contribuyendo así a la resolución del caso. La acción de la intéprete, basado en la realidad, llevada al teatro sin un efecto de «ilusión», impacta en la realidad fuera del teatro en una especie de ironía que confirma el poder de la simulación. Tal como comenta Arias sobre la anécdota: "La obra había producido un efecto más allá de la obra, sobre la ley" (Arias, 2019, p. 45).

La realidad que Arias presenta en su teatro, al negarse la condición ilusionista, juega con la simulación en un mecanismo que está abierto al espectador, colocando la fábrica de herramientas que componen ese teatro al descubierto. La realidad es una construcción propia -basada en lo autobiográfico- cuando es ella quien narra sus recuerdos, como es en el caso de $\mathrm{Me}$ lancolía y otras manifestaciones; o bien, basada en la realidad de otros. La simulación deja en claro que lo construido es un mecanismo alternativo a lo inaccesible que resulta lo real. Este aspecto parece ser comprendido intuitivamente por la madre de Arias, quien ante la pregunta que le hace un espectador al final de la obra sobre si se sintió bien representada, res- 
ponde: "Esa que está en la obra no soy yo; esa es la madre de mi hija" (Arias, 2019, p. 47).

\section{Conclusión}

Como hemos mostrado a partir de la obra de Lola Arias, el teatro documental se basa en concepciones artísticas-sociales las cuales buscan anualar la separación binaria entre arte y vida, artista y público, así como realidad y ficción. Esas ideas ya tuvieron sus raíces en el teatro político de la primera mitad del siglo XX y fueron más desarrolladas en el ámbito de la crítica posmoderna a partir de la década de los 80 del siglo pasado. Tanto el collage como el simulacro, elementos que comunmente asociamos con el discurso posmoderno, son recursos ampliamente usados dentro de las obras de Arias. Mientras hoy en día, la discusión sobre modernidad y posmodernidad ha perdi- do importancia y actualidad, sin duda muchas de las herramientas e ideas inspiradas por esta crítica influyen y siguen teniendo su presencia en el arte actual en muchas partes del mundo.

El teatro documental latinoamericano, y específicamente la obra de Arias, sigue ampliando cada vez más sus posibilidades de acuerdo con los contextos en donde se presenta. Es un teatro que busca alternativas ante todo aquello que parece difuminarse y que está más allá del teatro, es decir, en lo que podría comprenderse como real -los hechos, la historia-, para exponer su inaccesabilidad poniendo en evidencia el engaño. De ahí su carácter político capaz de observarse no sólo en la intencionalidad de transformar la concicencia de sus espectadores, sino también de implicarlos, hacerlos partícipes, no sólo activando sus cualidades inteletuales sino también las sensoriales y empíricas.

\section{BIBLIOGRAFÍA}

Arias, L. (2019). Tres obras hermanas. Paso de Gato: Revista Mexicana de Teatro, 76, 44-47.

Arias, L. (Sin fecha). Lola Arias. Recuperado de: http://lolaarias.com/bio/

Artaud, A. (1978). El teatro y su doble. Barcelona: Edhasa.

Baudrillard, J. (1978). Cultura y simulacro. Barcelona: Kairós.

Bravo-Elizondo, P. (1982). El teatro documental latinoamericano. México: Universidad Nacional Autónoma de México.

Brownell, P. y Hernández, P. (2019). El teatro documental de Vivi Tellas. Biodrama.

Proyecto Archivos. Paso de Gato, 76, 26-27.

Brownell, P. (2012). Proyecto Archivos: El teatro documental según Vivi Tellas. Emisférica, 9, 1-5.

De Vicente, C. (2016). El teatro en la realidad: Once notas sobre el teatro documento. Revista Artescena, 2, 34-45.

Hernández, P. (2011). Biografías escénicas: Mi vida después de Lola Arias. Latin

American Theatre Review, 45 (1), 115-128.

Huyssen, A. (1998). En busca de la tradición: vanguardia y postmodernismo en los

años 70. En Pico, J. (ed.), Modernidad y Postmodernidad (pp. 141-164). Madrid:

Alianza.

Lyon, D. (2000). Postmodernidad. Madrid: Alianza.

Pavis, Patrice (1998). Diccionario del teatro. Paidos: Barcelona.

Yúdice, G. (1989). ¿Puede hablarse de postmodernidad en América Latina? Revista de

Crítica Literaria Latinoamericana, 15 (29), 105-128. 